\title{
FIELD EXPERIMENTS TO DETERMINE THE EFFECT OF A DEBRIS LAYER ON ABLATION OF GLACIER ICE
}

\author{
by \\ M. Nakawo \\ (Geotechnical Section, Division of Building Research, National Research Council of Canada, \\ Ottawa, Ontario K1A OR6, Canada) \\ and G. J. Young \\ (Snow and Ice Division, National Hydrology Research Institute, Inland Waters Directorate, \\ Environment Canada, Ottawa, Ontario K1A OE7, Canada)
}

\section{ABSTRACT}

Ablation of glacier ice has been observed with artificial debris layers prepared with Ottawa sand (ASTM C-109) ranging from 0.01 to $0.1 \mathrm{~m}$ thick. Data on external variables observed during the experiments and determination of physical constants of the debris layers have allowed the testing of a proposed simple mode1. Theoretical predictions compare favourably with the observations. Discussion is extended to a proposal for a simple method by which ablation under a debris layer could be estimated even if the thermal conductivity or thermal resistance of the material were unknown.

\section{INTRODUCTION}

Glacier termini are commonly characterized by the presence of large quantities of debris, existing both within and on top of the glacier ice. The surface debris cover largely controls the rates of ice melt which, in turn, affects the mode of formation of glacially deposited landforms. The purpose of this paper is to investigate the effect of surface debris on rates of ice melt.

Quantitative assessment of ablation rate under a debris layer can also be significant for studies of glacier mass balance (Inoue 1977), glacier dynamics (Glazyrin 1975, Nakawo 1979), and giacial history (Bondarev 1961, Kite and Reid 1977, Whalley 1979). It is an essential factor in any understanding of the formation and decay of dirt cones on glacier surfaces (Sharp 1949, Boulton 1967, Drewry 1972). It is possible, furthermore, that it could lead to useful application of artificial ablation control and be adopted for engineering and hydrological purposes (Grove and others 1963, Williams and Gold 1963, Higuchi 1973).

The ablation rate under a debris layer is a function of external variables including radiation and air temperature, as well as physical characteristics of the layer such as thickness, albedo, and thermal conductivity. The effect of the debris layer on ablation of glacier ice should be studied in association with these variables.

Observations have been made to evaluate the effect of a debris layer on ablation of glacier ice, snow, and lake ice (0strem 1959 Wijngaarden 1961, Loomis 1970, Moribayashi and Higuchi 1972, Small and Clark 1974, Fujii 1977). These studies suggest that a very thin debris cover may accelerate melting, while an increasing thickness of debris inhibits melting. Few studies, however, have considered the effects of both the external variables and the physical properties of the debris material. Kraus (1971) proposed a comprehensive theory for the ablation under a debris layer, taking various external variables into consideration. To the present authors' knowledge, however, the theory has not been tested against observed data.

In the past the major difficulty in examining theoretical prediction has been lack of reliable data. It is difficult to determine, in particular, the physical properties of debris material in the field. Artificial debris layers were therefore prepared using a known material in order to examine the effect of these layers on ablation of glacier ice. Ottawa sand (American Society for Testing and Materials $c-109$ ) was chosen as the material since many of its physical properties are known.

\section{EXPERIMENTS}

The experiments were carried.out at Peyto Glacier $\left(57^{\circ} 41^{\prime} \mathrm{N}, 116^{\circ} 33^{\prime} \mathrm{W}\right)$ in the Rocky Mountains, Alberta, Canada, from 20 to 22

August 1979. Six plots were prepared with dried ottawa sand on relatively flat ice near the snout of the glacier. They were aligned perpendicular to the prevailing wind direction and spaced about $0.1 \mathrm{~m}$ apart. Each plot was $0.3 \mathrm{~m}$ square and of thicknesses $h$, given in Table $I$. The site was levelled so that, initially, the surface of each plot was horizontal.

Precautions were taken so that the debris surface merged smoothly with the surrounding ice surfaces, but this was not successful because of local irregularities and general inclination ( $7^{\circ}$ leeward) of the original glacier surface. As the experiment progressed, moreover, differential ablation accentuated the irregularities between the debris surface and the surrounding ice surface. At plots $E$ and $F$ the debris surface, which was originally prepared to be 
TABLE 1. ARTIFICIAL DEBRIS LAYER AT EXPERIMENTAL SITE

SITE

\begin{tabular}{|c|c|c|c|c|c|c|}
\hline Thickness, $h \times 10^{-2} \mathrm{~m}$ & $0.86 \pm 0.18$ & $1.52 \pm 0.23$ & $1.92 \pm 0.36$ & $3.26 \pm 0.30$ & $5.16 \pm 0.29$ & $10.68 \pm 0.3$ \\
\hline Water content, $\omega=W_{w} / w_{d}$ & 0.224 & 0.205 & 0.220 & 0.173 & 0.085 & 0.175 \\
\hline Surface condition & wet & wet & wet & partly dry & dry & dry \\
\hline $\begin{array}{l}\text { Thickness of dry layer, } \\
h_{\mathrm{d}} \times 10^{-2} \mathrm{~m}\end{array}$ & $-\cdot$ & - & - & $\approx 0$ & 1.5 & 0.5 \\
\hline Specific heat capacity $C_{w} \times \mathrm{J}_{\mathrm{g}}^{-1} \mathrm{deg}^{-1}$ & 1.45 & 1.41 & 1.44 & 1.33 & 1.10 & 1.34 \\
\hline $\begin{array}{l}\text { Thermal conductivity } \\
K_{\mathrm{m}} \times \mathrm{w}^{-1} \mathrm{~m}^{-1} \mathrm{deg}^{-1}\end{array}$ & 2.28 & 2.23 & 2.27 & 2.13 & 1.04 & 1.87 \\
\hline
\end{tabular}

\section{Thermal resistance}

$R \times 10^{-3} \mathrm{~m}^{2} \mathrm{deg}^{-1} / \mathrm{W}$

$3.77 \pm 0.796 .82 \pm 1.03 \quad 8.46 \pm 1.5915 .31 \pm 1.41 \quad 49.62 \pm 8.25 \quad 57.11 \pm 5.52$

Dry density $\gamma_{d}=1560 \pm 120 \mathrm{~kg} \mathrm{~m}^{-3}$

horizontal, inclined gradually towards the south as ablation proceeded. The inclination was $17^{\circ}$ and $9^{\circ}$ at $E$ and $\Gamma$, respectively, at the end of the experiments; no slant developed at the other plots.

The dry density of the Ottawa sand $r_{d}$ was determined to be $1560 \pm 120 \mathrm{~kg} \mathrm{~m}^{-3}$ when the sites were prepared (evening of 20 August). On the morning of 21 August, however, the debris surface appeared to have become saturated with water at plots $A, B, C$, and $D$. This continued throughout the observation period and the water content ( $\omega=$ mass of water $w_{W}$ /mass of dry sand $w_{d}$ ) for each plot was determined at the end of the experiments (Table I). The water seemed to be distributed uniformly in the debris at each plot. The debris surface was apparently dry at plots $E$ and $F$; however, a wet layer was observed near the bottom of the debris material at both plots. A distinct boundary was found between the dry layer near the surface and the wet layer near the bottom. The thickness of the dry layer $h_{d}$ as well as the bulk water content $w$ were measured at both plots (Table I). Ablation during a given period was determined by measuring the increase in the distance between the debris surface and a string installed horizontally over the site at the beginning of the experiments. For each measurement five readings were taken at marked locations within each plot. The ablation of the bare ice beside the plots was measured by the same procedure.

Atmospheric pressure $p$, air temperature $T_{\mathrm{a}}$, and humidity were continuous ly recorded at the base camp established on a lateral moraine about $600 \mathrm{~m}$ from the site. The temperature and humidity readings were correlated with the data, measured with an Assmann ventilated psychrometer at the site to take into account the differences between conditions at the base camp and those at the site. Incoming short-wave radiation was measured with a Sol-A-Meter (Matrix Inc.), which provides a read-out of total integrated insolation. Readings were taken every 1 to $3 \mathrm{~h}$ during the day. In addition, wind speed $u$, cloud amount $a_{c}$, and cloud type were recorded.

\section{OTTAWA SAND}

Ottawa sand (ASTM C-109) is a typical silica sand of medium grain size. The average grain diameter is $0.4 \mathrm{~mm}$ and more than $90 \%$ by weight falls into a range of 0.2 to $0.6 \mathrm{~mm}$ in diameter (Baker 1976). Specific gravity and specific heat of dry Ottawa sand are $2650 \mathrm{~kg} \mathrm{~m}^{-3}$ and $0.84 \mathrm{~J} \mathrm{~g}^{-1} \mathrm{deg}^{-1}$ respectively (Jumikis 1977). The specific heat capacity of the debris layer $C_{W}$ is shown in Table I.

The thermal conductivity of Ottawa sand $K_{m}$ was measured intensively by Kersten (1949) for a variety of water contents $\omega$, dry densities $\gamma_{d}$, and temperatures. His results for $\gamma_{d}=$ $1560 \mathrm{~kg} \mathrm{~m}^{-3}$ at $4^{\circ} \mathrm{C}$ are plotted against water content $\omega$ in Figure 1. Slusarchuk and Foulger (1973) also measured conductivity at $4^{\circ} \mathrm{C}$ for extreme cases of water content, but their dry density value was larger than that obtained at the plots on the glacier. Their results were therefore corrected for $\gamma_{d}=1560 \mathrm{~kg} \mathrm{~m}^{-3}$ by a relation between $K_{m}$ and $\gamma_{d}$ given by Kersten (1949) and are presented in Figure 1.

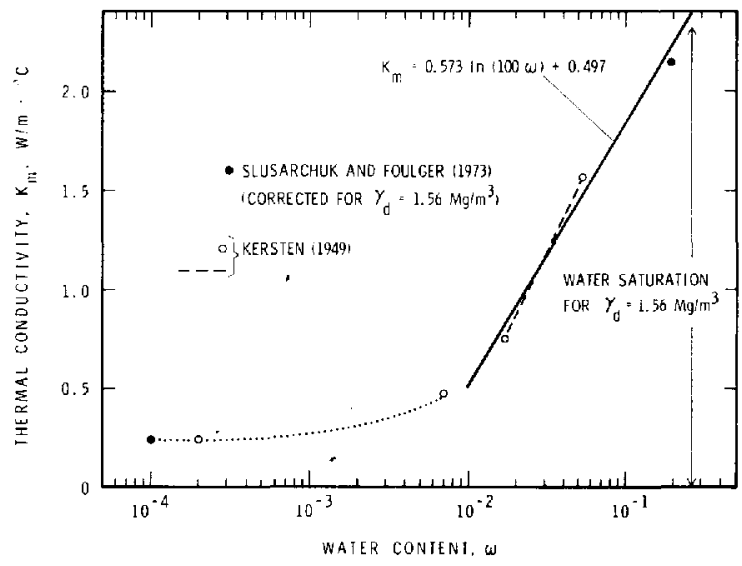

Fig.1. Thermal conductivity of Ottawa sand for $\gamma_{d}=1560 \mathrm{~kg} \mathrm{~m}^{-3}$ at $4^{\circ} \mathrm{C}$ versus water content.

The variation of $K_{\mathrm{m}}$ with increase in $w$ is very small when $\omega<0.01$. For $\omega>0.01$, on the other hand, $k_{m}$ increases rapidly; the trend may be represented by

$$
K_{\mathrm{m}}=0.573 \ln (100 \omega)+0.497,
$$

where $K_{m}$ is given by $\mathrm{W} \mathrm{m}^{-1} \mathrm{deg}^{-1}$. This form of relation between $K_{m}$ and $\omega$ for relatively large water contents was established by Kersten

(1949) for various kinds of soils.

Thermal conductivity $k_{m}$ at plots $A, B$, 
$C$, and $\mathbf{C}$ was estimated by means of Equation (1) using the bulk water content w given in Table I. The water content in the dry layer at plots $E$ and $F$ was assumed to be 0.01 , since the variation of $K_{\mathrm{m}}$ with $\omega$ is very small for $\omega<0.01$. This value was used to calculate the water content of the wet layer at the two locations. The value of $k_{\mathrm{m}}$ was obtained for each layer using Equation (1). The bulk conductivity for the sites was then estimated using a series model of two layers. All the estimated $K_{m}$ values for each plot are given in Table I, in which the thermal resistance $R\left(=h / K_{\mathrm{m}}\right)$ for each location is also shown. The albedo of Ottawa sand was measured later for wet and dry surface conditions in relation to solar altitude. It decreased for dry (wet) conditions uniformly (almost linearly) from $0.51(0.31)$ to $0.32(0.28)$ as solar altitude increased from 15 to 50 deg, this range in solar altitude being encountered during the observation period. The results compared favourably with those reported by Büttner and Sutter (1935) and Friedrich (1965).

4. MODEL

The energy balance equation at a debris surface is given by

$$
C=E+H+E
$$

where $C, F, H$, and $E$ are conductive heat flux into the debris, radiation flux, sensible heat flux, and latent heat flux, respectively. All the terms are taken to be positive downward. The energy balance equation at the debris/ice interface is

$$
C^{\prime}=M+C^{\prime \prime}
$$

where $M$ is the heat used for ice ablation during a unit period, and $C^{\prime}$ and $C^{\prime \prime}$ are conductive heat fluxes from the debris and towards the ice, respectively, again taken to be positive downward. The difference between $C$ and $C^{\prime}$ gives the change in heat stored in the debris layer. $M$ is given by

$$
M=L_{f} \rho_{j} r
$$

where $L_{f}$ is the latent heat of fusion $\left(334 \mathrm{~J} \mathrm{~g}^{-1}\right), \rho_{i}$ is the density of ice (assumed to be $900 \mathrm{~kg} \mathrm{~m}^{-3}$ ), and $r$ is the ablation rate. Three assumptions are made, that: $C^{\prime \prime}=0$, which is valid for a temperate glacier and is certainly valid for the site during August; $c=C^{\prime}$, stored heat in the debris layer is constant; and the temperature in the debris layer is in a stationary state: a linear profile for a uniform debris layer. Using these assumptions

$$
\begin{aligned}
& M=F+H+E, \\
& M=\frac{K_{\mathrm{m}}}{h} T_{\mathrm{S}}=\frac{T_{\mathrm{S}}}{R}
\end{aligned}
$$

where $h$ is the debris thickness, $K_{\mathrm{m}}$ is the thermal conductivity, $R$ is the thermal resistance, and $T_{S}$ is the surface teiliperature of the debris in ${ }^{\circ} \mathrm{C}$.

$$
\text { The following expressions were assumed }
$$
for $E, H$, and $E$ (Sutton 1953, Geiger 1965, Munn 1966):

$$
F=(1-\alpha) G+A-\sigma\left(T_{5}+273\right)^{4},
$$

where $\alpha$ is the surface albedo of the debris, $G$ is the global radiation, $A$ is the atmospheric radiation, and $\sigma$ is the Stephan-Boltzmann constant $\left(5.67 \times 10^{-8} \mathrm{~W} \mathrm{~m}^{-2} \mathrm{~K}^{4}\right)$;

$$
H=\beta u_{\mathrm{a}}\left(T_{\mathrm{a}}-T_{\mathrm{s}}\right),
$$

where $B$ is the coefficient of heat transfer $\left(4.89 \pm 1.16 \mathrm{~J} \mathrm{~m}^{-3} \mathrm{deg}^{-1}\right.$ compiled by Naruse and others (1970) from the data for $\beta$ obtained at various surfaces of glaciers, snow fields and artificial basins), $u_{a}$ is the wind speed, and $T_{a}$ is the air teniperature at the site; and

$$
E=\beta L_{\mathrm{e}} \frac{0.623}{p c_{\mathrm{p}}}\left(e_{\mathrm{a}}-e_{\mathrm{s}}\right)
$$

where $L_{\mathrm{e}}$ is the latent heat of evaporation (2 $494 \mathrm{Jg}^{-1}$ ), $p$ is the atmospheric pressure, $e_{p}$ is the specific heat capacity of air $\left(1.0 \mathrm{~J} \mathrm{~g}^{-1} \mathrm{deg}^{-1}\right), e_{a}$ is the vapour pressure in air, and $e_{s}$ is the vapour pressure at the surface.

With Equations (4) to (9) one can estimate $r$ for a given $R$ when the external variables $G, A, u_{a}, T_{a}, p, e_{a}$, and $e_{s}$ are given. This model is rather more practical than the one proposed by Kraus (1975), a lthough the basic assumptions and the expressions are similar.

\section{ANALYSIS}

Values of the external variables for the observation period are compiled in Table II. Reflected radiation is a function of albedo, which is dependent on solar altitude and, accordingiy, on time. Total reflected radiation for each period was estimated by summing each reading of global radiation, which had been multiplied by albedo at the time of the reading. Average reflected radiation in Table II was obtained by dividing the total reflected amount by the length of each period. Nominal average albedo for each day depends on cloud cover and other factors because albedo is time-dependent. The values calculated for 21 August, however, were similar to those calculated for 22 August $(0.288$ and 0.287 for wet surface on the 21 st and 22nd, respectively, and 0.374 and 0.372 for dry surface on the 21st and 22nd, respectively).

Atmospheric radiation $A$ was estimated by a Brunt-type empirical equation proposed by Kondo (1967)

$$
A=\sigma\left(T_{\mathrm{a}}+273\right)^{4}\left\{1-\left(0.49-0.066 \sqrt{e_{\mathrm{a}}}\right)\right.
$$

where $T_{\mathrm{a}}$ is in degrees Celsius, $e_{\mathrm{a}}$ is in $10^{3} \mathrm{~Pa}$ and $C$ is a parameter determined by $e_{a}$, cloud amount $\alpha_{C}$, and cloud type. The estimated results for the periods of daylight are also tabulated in Table II. As cloud amount and type were not observed during night time, $A$ was assumed to be as shown in parentheses in Table II.

\subsection{Wet surface}

It was assumed that the air at the debris surface was saturated at $T_{\mathbf{S}}$ for a wet surface, that $\beta$ was equal to $4.89 \mathrm{~J} \mathrm{~m}^{-3} \mathrm{deg}^{-1}$ and that external variables had the values given in Table II. The dependence of the ablation rate $p$ on thermal resistance $R$ was thus determined, using Equations (4) to (9), by eliminating $T_{5}$. The results are shown by solid lines in Figures 2 and 3 . They indicate a general asymptotic decrease of $r$ as $R$ increases.

For a given $R$, one can also estimate each flux component. $F$ is essentially a constant because $\left|T_{S}\right| \ll 273$ for a realistic range of $R$. $H$ and $E$, on the other hand, decrease from positive to negative with increase in $R$. For a small $R$ (very thin debris layer), $T_{\mathrm{S}}$ being close to the ice temperature $\left(0^{\circ} \mathrm{C}\right)$, heat is 
TABLE II. EXTERNAL VARIABLES DURING OBSERVATION PERIOD

\begin{tabular}{|c|c|c|c|c|}
\hline & $\begin{array}{c}20-21 \text { August } \\
\text { (night) }\end{array}$ & $\begin{array}{l}21 \text { August } \\
\text { (day) }\end{array}$ & $\begin{array}{l}21-22 \text { August } \\
\text { (night) }\end{array}$ & $\begin{array}{l}22 \text { August. } \\
\text { (day) }\end{array}$ \\
\hline Atmospheric pressure $p, 10^{3} \mathrm{~Pa}$ & 803.1 & 803.1 & 803.1 & 803.1 \\
\hline Mean air temperature $T_{a},{ }^{\circ} \mathrm{C}$ & -0.91 & 5.35 & -0.26 & 5.97 \\
\hline Mean vapour pressure $e_{\mathrm{a}}, 10^{3} \mathrm{~Pa}$ & 10.17 & 8.17 & 10.56 & 10.17 \\
\hline Wind speed $u_{a}, m / s$ & $(4-5)$ & $4-5$ & $(4-5)$ & $4-5$ \\
\hline Average global radiation $G, \mathrm{~W} \mathrm{~m}^{-2}$ & 0.0 & 525.3 & 0.0 & 340.2 \\
\hline wet & 0.0 & 151.0 & 0.0 & 97.7 \\
\hline dry & 0.0 & 196.4 & 0.0 & 126.6 \\
\hline Cloud amount $a_{c}$ in tenths and cloud type & $?$ & $\begin{array}{r}3.5 \\
\text { cirrus }\end{array}$ & $?$ & $\begin{array}{c}5.2 \\
\text { al tocumulus }\end{array}$ \\
\hline Atmospheric radiation $A, \mathrm{~W} \mathrm{~m}^{-} 2$ & $(252.7)$ & 252.7 & $(284.1)$ & 315.4 \\
\hline
\end{tabular}

Wind speed $u_{a}$, cloud amount $a_{c}$, and cloud type were not observed during night time.

Numerical values in parentheses were assumed for the estimation described in Section 5.

transported from the ambient air to the debris surface (positive $H$ and $E$ (condensation)), leading to a large ablation rate. For a large $R, M$ (and hence $r$ ) being $c$ lose to zero owing to the insulation effect of the layer, the energy is almost balanced at the debris surface by the three flux components $E, H$, and $E$. Consequently, $B$ and $E$ become negative (see Equation (5)). $H=0$ when $T_{\mathrm{a}}=T_{\mathrm{S}}$ and $E=0$ when $e_{a}=$ saturation vapour pressure for $T_{s}$. Dotted lines in Figures 2 and 3 show the estimated ablation rates with upper and lower

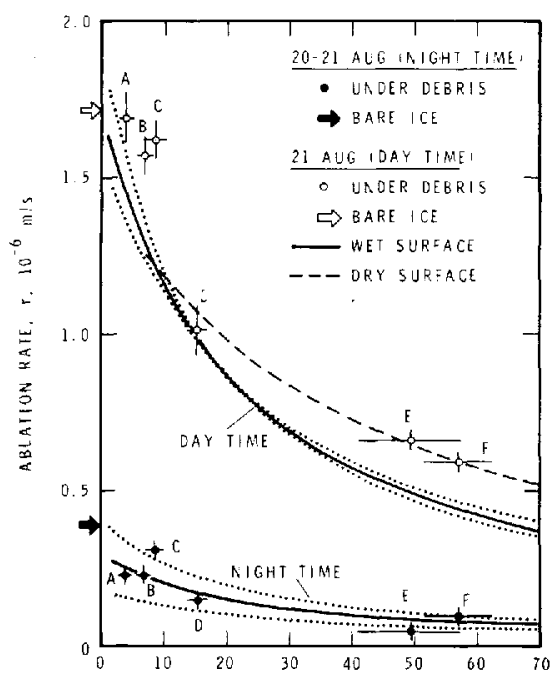

THERMAL RESISTANGE. R. $10^{-3} \mathrm{~m}^{2} \mathrm{c} W$

Fig.2. Ablation rate versus thermal resistance for 20-21 August. Calculations for wet surface with $\beta=4.89 \mathrm{~J} \mathrm{~m}^{-3} \mathrm{deg}^{-1}$ shown by solid tines, $B=4.89 \pm 7.16 \mathrm{~J} \mathrm{~m}^{-3} \mathrm{deg}^{-1}$ shown oy dotted Iines; broken Iine shows calculation for dry surface.

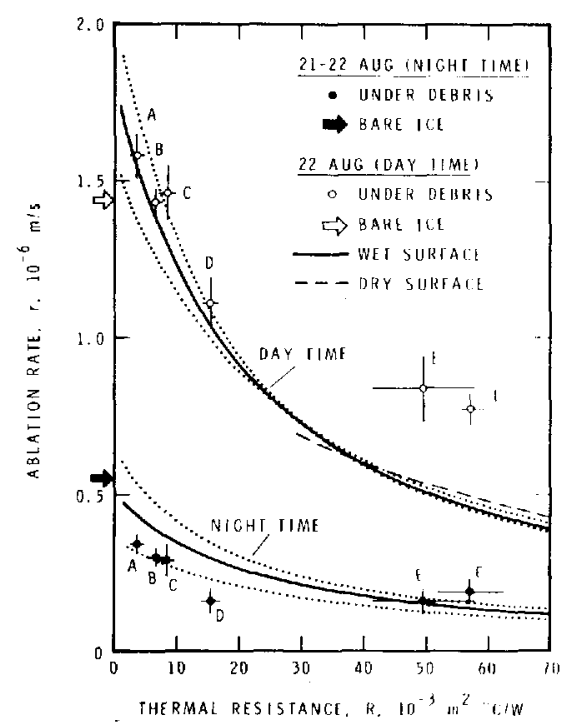

Fig.3. Ablation rate versus thermal resistance for 21-22 August. Calculations for wet surface with $B=4.89 \mathrm{~J} \mathrm{~m}^{-3} \mathrm{deg}^{-1}$ shown by solid 7ines, $\beta=4.89 \pm 1.16 \mathrm{~J} \mathrm{~m}^{-3} \mathrm{deg}^{-1}$ shown by dotted lines; broken line shows calculation for dry surface.

$\beta$ values of $4.89+1.16 \mathrm{~J} \mathrm{~m}^{-3} \mathrm{deg}^{-1}$ and 4.89 $1.16 \mathrm{~J} \mathrm{~m}^{-3} \mathrm{deg}^{-1}$, respectively. The larger $\beta$ value predicts a larger ablation rate. It may be seen that the effect of $\beta$ value (deviation of the dotted lines from the solid line) decreases as $R$ increases for night time. The same tendency may be observed during the day, but the deviation becomes zero at an $R$ value where $H+E=D$. As $R$ increases further, the deviation becomes larger, but in the opposite sense; the larger $\beta$ value is associated with a smaller ablation rate. 


\subsection{Dry surface}

The assumption of saturated vapour pressure at the surface, made for the above calculation, would be valid for wet-surface conditions; it would be valid for apparently dry surfaces, as well, when condensation occurs. This was the case during the night time. It was considered, therefore, that the ablation rate for a dry surface during night time was the same as for a wet surface. During the day time, however, it would be reasonable to assume for a dry surface that $e_{S}=e_{a}$, i.e., that $E=0$.

The calculated ablation rate for a dry surface (with this assumption) is shown by dashed lines in Figures 2 and 3 . The value of $B$ was taken to be $4.89 \mathrm{~J} \mathrm{~m}^{-3} \mathrm{deg}^{-1}$ in the calculations. When values of $\beta=4.89 \pm 1.16$ $\mathrm{J} \mathrm{m}^{-3} \mathrm{deg}^{-1}$ were used, the variation in $r$ for given $R$ was almost the same as for the calculations for wet surfaces.

The value of $F$ for dry surfaces is smaller than that for wet surfaces because of the larger albedo of a dry surface. The predicted ablation rate is therefore smaller for dry surfaces than for wet surfaces, when $R$ is sma11, where condensation occurs for both conditions. At a large $R$ value, however, the ablation rate for dry surfaces is predicted to be larger than for wet surfaces. For large $R$, the difference in evaporation loss between wet and dry surfaces is too large to be compensated by the difference in $F$ for the two conditions.

\section{DISCUSSION}

observed ablation rates at the site are plotted in Figures 2 and 3 using solid circles for the night-time observations and open circles for day. Ablation rates of bare ice beside the plots are also shown with solid (night time) and open (day time) arrows as reference. The bare ice surface was dirty and its albedo observed to be $0.32 \pm 0.02$ near noon when solar altitude was about $50^{\circ}$.

The predicted ablation rate compared reasonably well with the observed results. (Note that results atplots $E$ and $F$ during day time are to be compared with the broken lines, not with the solid lines.)

For small $R$ values a larger ablation rate than predicted was observed at plots $A$, $B$, and $C$ during day time, suggesting that the actual value of $\beta$ could be slightly larger than the value used for the calculations. This is reasonable since surface roughness is greater at the site than at the natural surface owing to the presence of the plots. The predicted values for plots $E$ and $F$ during day time on 22 August are also smaller than the observed ablation rate. This discrepancy is probably caused by an increase in inclination of the debris surface towards the south, as mentioned in section 2.

The general agreement between the predicted and observed results suggests that one can predict ablation if the external variables and thermal resistance of the debris layer are known. Determination of thermal resistance, however, is a most difficult problem for an unknown debris material in the field.

The mode 7 described in section 4 could also be used to predict surface temperature $T_{S}$ by eliminating $M$ from Equations (5) and (6) Estimation was made using the data for external variables obtained between 11.15 and $13.45 \mathrm{~h}$ local time on 21 August. The predicted surface temperature is shown in Figure $4 a$ with solid (wet surface) and broken (dry surface) lines. The ablation rate was also estimated for this

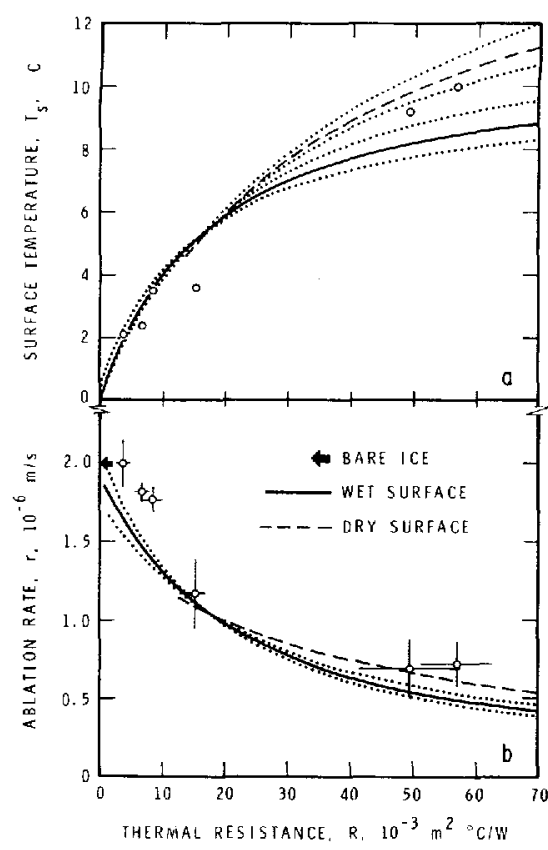

Fig.4. Surface temperature (a) and ablation rate (b) versus thermal resistance from 11.15 to $13.45 \mathrm{~h}$ local time, 21 August; surface temperature measured at $12.40 \mathrm{~h}$ local time. Calculations for wet surface with $\beta=4.89 \mathrm{~J} \mathrm{~m}^{-3} \mathrm{deg}^{-1}$ shown with solid lines; calculations for dry surface with

$\beta=4.89 \mathrm{~J} \mathrm{~m}^{-3} \mathrm{deg}^{-1}$ shown with broken lines; calculations for both wet and dry surfaces with $\beta=4.89 \pm 1.16 \mathrm{~J} \mathrm{~m}^{-3} \mathrm{deg}^{-1}$ shown by dotted lines.

rather short period by means of the same procedure (Fig. $4 \mathrm{~b}$ ). Observed ablation rates during this period and surface temperature measured at $12.40 \mathrm{~h}$ local time are also plotted for comparison. The estimated and observed values agree favourably for both surface temperature and ablation rate. It should be possible, therefore, to estimate thermal resistance from surface temperature measurements using Equations (5) to (9).

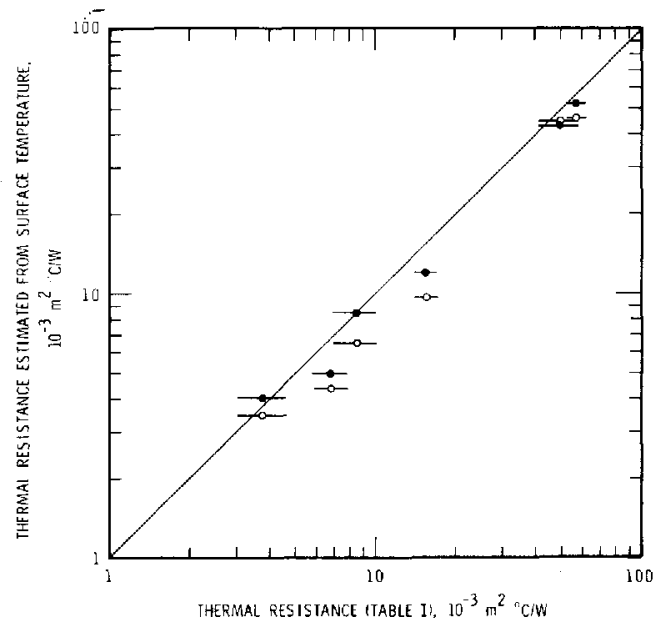

Fig.5. Comparison of thermal resistances at sites estimated from surface temperature with values obtained from the physical constants of 0ttawa sand. Estimations made from ablation rate (open circles) and external parameters (solid circles). 
The estimates were made using observations for the noon period on 21 August. Estimated thermal resistance is compared in Figure 5 (solid circles) with the resistance given in Table I. Thermal resistance was obtained also from the data on surface temperature and ablation rate using Equations (4) and (6), but this method is not of practical interest because ablation rate is not usually known and is the term to be deternined. Values obtained by this method are also compared in Figure 5 (open circles) with the values given in Table I. Thermal resistances obtained by the three different methods compare reasonably well with each other.

It is fairly easy to determine the surface temperature of a debris layer over a wide area by means of remote sensing. One can estimate, therefore, the thermal resistance and consequently the ablation rate under the debris layer from a knowledge of external variables only. The model now proposed neglects the change of stored heat in a debris layer, although it could be significant for a thick layer with a large heat capacity. Neither is the effect of rainfall included. Significant heat could be transported by water percolation into a porous, thick debris layer (Yoshida, unpublished). For a very thin, or scattered, debris layer on a glacier surface, albedo must be considered as a variable. Such a situation is outside the scope of the present paper, but it is an important consideration since accelerated ablation takes place when this condition prevails (Megahan and others, 1970, Higuchi and Nagoshi 1975. Further study will be necessary on this subject.

\section{ACKNOWLEDGEMENTS}

The authors are grateful for the assistance given in the field by $N$. Maeno and $H$. Narita of the Institute of Low Temperature Science, Hokkaido, Japan, and are indebted to L.W. Gold of the Division of Building Research, National Research Council of Canada, for reviewing the manuscript

This paper is a contribution from the Division of Building Research, National Research Council of Canada, and is published with the approval of the Director of the Division.

\section{REFERENCES}

Baker T W H 1976 Preparation of artificially frozen sand specimens. National Research Counciz of Canada. Division of Building Research. DBR Paper 682

Bondarev $L G 1961$ Evolution of some Tien Shan glaciers during the last quarter of tne century. Intemational Association of Scientific Hydrology Eublication 54 (General Assembly of Helsinki 1960, Snow and Ice): 412-419

Boulton G 51967 The development of a complex supraglacial moraine at the margin of Sørbreen, Ny Friesland, Vestspitsbergen. Journat of Glaciology 6(47): 717-735

Büttner K, Sutter E. 1935 Die Abkühlungsgrösse in den Dünen. Rückstrahlung verschiedener Bodenbedeckungen für ultraviolette und gesamte Sonnenstrahlung. Strahlentherapie 54: $156-173$

Drewry D J 1972 A quantitative assessment of dirt-cone dynamics. Joumal of Glaciology 11(63): $431-446$

Friedrich $V 1965$ The dependence of albedo on solar elevation. Pure and Applied Geophysics 60: 197-200
Fujii Y 1977 Field experiment on glacier ablation under a layer of debris cover. Joumal of the Japanese Society of Snow and Ice (Special Issue) 39: 20-21

Geiger R 1965 The climate near the ground. Cambridge, MA, Harvard University Press (Translated from the fourth German edition of Das Klima der bodennahen Luftschicht. Brunswick, Germany, 1961

Glazyrin GE 1975 The formation of ablation moraines as a function of the climatological environment. Intemational Association of Hydrological Sciences Publication 104 (General Assembly of Moscow 1971, Snow and Ice): 106-110

Grove C S Jr, Grove S T, Aidun A R 1963 The theory and use of aqueous foams for protection of ice surfaces. In Kingery W D (ed) Ice and snow : a symposium. Cambridge, Massachusetts, MIT Press: 666-684

Higuchi $K 1973$ on the possibility of artificial control of the mass balance of a perennial snow patch. International Association of Scientific Hydrology Publication 95 (Symposium of Cambridge 1969, Hydrology of GLaciers): 207-212

Higuchi K, Nagoshi A 1975 Effect of particulate matter in surface snow layers on the albedo of perennial snow patches. Intemational Association of Hydrological Sciences Publication 118 (General Assembi of Grenoble 1975, Isotopes and Impurities in Snow and Ice): 95-97

Inoue J 1977 Mass budget of Khumbu glacier. Joumat of the Joponese Society of Snow and Ice 39 (Special Issue): 15-19

Jumikis A R 1977 Thermal geotechnics. New Brunswick, NJ, Rutger University Press

Kersten M S 1949 Thermal properties of soils. University of Minnesota. Institute of Technology. Engineering Experiment Station 52 (21) (Buzzetin 28)

Kite GW, Reid I A 1977 Volumetric change of the Athabasca Glacier over the last 100 years. Joumal of Hydrology $32(3-4)$ : $279-294$

Kondo $\mathrm{J} 1967$ Analysis of solar radiation and downward long-wave radiation data in Japan. Scientific Reports of Tohoku University Ser 5, 18: 91-124

Kraus $H 1975$ An energy balance model for ablation in mountainous areas. Inter. national Association of Hydrological Sciences publication 104 (General Assembly of Moscow 1971, Snow and Ice): 74-82

Loomis S R 1970 Morphology and ablation processes on glacier ice. Proceedings of the Association of American. Geographers 2 88-92

Megahan W F, Meiman J R, Goodell B C 1970 The effect of albedo-reducing materials on net radiation at a snow surface. Bulletin of the Intemational Association of Scientific Hydrology 15(1): $69-80$

Moribayashi S, Higuchi K 1972 Yüsetsu no jinkō yokusei ni kansuru kisoteki kenkyū [On experiments on reducing the melting of snow]. Joumal of the Japanese Society of Snow a.td Tce 34(4): 165-172

Munn RE 1966 Descriptive micrometeorology. New York, Academic Press

Nakawo $M 1979$ Supraglacial debris of G2 glacier in Hidden Valley, Mukut Himal, Nepa 1. Joumal of Glaciology 22(87): 273-283.

Naruse R, Dura H, Kojima K 1970 Kion-yūsetsu no yagai kenkyū [Field studies on snow melt due to sensible heat transfer from 
the atmosphere]. Low Temperature Science Ser $A, 28:$ 191-202

Dstrem G 1959 Ice melting under a thin layer of moraine, and the existence of ice cores in moraine ridges. Geografiska Annaler $41(4)$ : $228-230$

Sharp R P 1949 Studies of the supraglacial debris on valley glaciers. American Joumal of Science 247(5): 289-315

Slusarchuk W A, Foulger P H 1973 Development and calibration of a thermal conductivity probe apparatus for use in the field and laboratory. National Researeh Council of Canada. Division of Building Research. Technical Paper 388

Small R J, Clark M I 1974 The medial moraines of the lower Glacier de Tsidjiore Nouve, Valais, Switzerland. Joumal of Glaciology 13(68): 255-263

Sutton O G 1953 Micrometeorology: a study of physical processes in the lowest layers of the Earth's atmosphere. New York, McGraw$\mathrm{Hill}$.

Whalley W B 1979 The relationship of glacier ice and rock glacier at Grubengletscher, Kanton Wall is, Switzerl and. Geografiska Annaler 61A(1-2): 49-61

Wijngaarden $H$ van 1961 Investigations concerning the transport of heat through a solid sheet of ice in periods of frost and thaw. International Association of Seientific Hydrology Publication 54 (General Assembly of Helsinki 1960, Snow and Icel: 40-55

Williams G P, Gold L W 1963 The use of dust to advance the break-up of ice on lakes and rivers. Proceedings of the 1963 Annuai. Meeting of the Eactern Snow Conference: $31-56$

Yoshida M Unpublished. Higashi-nepāru_ni akeru debris covered glacier no netsushüshiteki tokusei ni kansuru kenkyu [A study on the characteristics of heat balance of the debris-covered glacier in east Nepal]. (M.Sc. thesis, Nagoya University, 1980) 